\title{
SENTENCIA DE LA I. CORTE DE APELACIONES DE LA SERENA SOBRE CONSTITUCIÓN DE PERTENENCIA MINERA
}

\author{
La Serena, tres de noviembre de mil novecientos noventa y nueve. \\ VISTOS:
}

Se eliminan los motivos primero a quinto contenidos en la sentencia en alzada.

\section{Y TENIÉNDOSE EN SU LUGAR Y ADEMÁS PRESENTE:}

$\left.1^{\circ}\right)$ Que en estos autos sobre constitución de las pertenencias mineras PAMELA 1 al 60, solicitada por la Compañía Minera Carmen de Andacollo, informando el Servicio Nacional de Geología y Minería al tenor de lo preceptuado en el artículo 79 del Código de Minería, se pronunció favorablemente acerca de los aspectos técnicos relacionados con la operación de mensura, su acta y plano concluyendo que ellas quedaban comprendidas tanto dentro del terreno manifestado como dentro del abarcado por la solicitud de mensura, señalando, además, que los hitos habían sido correctamente colocados. Sin embargo, el mismo informe observó, que dichas pertenencias abarcaban parcialmente la concesión minera de ENAMI, Tauro 1 al 77.

$2^{\text {o) }}$ Que debido a la superposición acusada, el juez aquo por resolución de fecha quince de julio del año 1998 , escrita a fojas 48 , dispuso la publicación, en extracto, de dicha circunstancia, con indicación de las coordenadas U.T.M., tanto de las pertenencias del interesado como las del presunto afectado, de acuerdo con los datos proporcionados en el mismo informe del organismo técnico, todo ello, en cumplimiento a lo señalado en el artículo 83 del Código de Minería. Exigencia que fue cumplida como costa del ejemplar del Boletín Oficial de Minería de Elqui agregado a fojas 49.

Consta, asimismo, que por resolución de treinta de octubre del año pasado, escrita a fojas 52, se dispuso la notificación personal a la persona a cuyo nombre figuraba inscrita la pertenencia afectada, para dar cumplimiento a la nueva exigencia estatuida en la Ley 19.573, publicada en el Diario Oficial del 25 de julio 1998, que modificó el artículo 83 del Código de Minería.

$3^{\text {o) }}$ Que mediante escrito aparejado a fojas 55, el abogado don Ariel González Carvajal por la peticionaria, hizo presente al tribunal que la dueña actual de las pertenencias Tauro 1 al 77 era precisamente su representada Compañía Minera Carmen de Andacollo, puesto que las había adquirido por aporte que de ellas hiciera la Empresa Nacional de Minería, por escritura de constitución de sociedad y estatutos de fecha 18 de julio de 1991. El título a favor de la Compañía constituyente corre inscrito a fojas 169 № 56 del Registro de Propiedad del Conservador de Minas de Elqui-Vicuña, correspondiente al año 1991. Para acreditar lo expuesto, acompañó a fojas 54 copia de la inscripción indicada. 
$4^{\circ}$ ) Que con tales antecedentes, el juez de la causa dictó sentencia definitiva de fecha veintiséis de marzo del año en curso, no dando lugar a la constitución de la concesión de explotación de autos, fundado en el artículo 27 del Código de Minería que dispone que sobre las sustancias concesibles existentes en terrenos cubiertos por una concesión minera, no puede constituirse otra, imponiendo al juez, por la modificación introducida a tal artículo por la Ley 19.573, la obligación de velar por la observancia de esta prohibición. Hizo también presente, en lo medular, que tal prohibición también comprendía el caso que la superposición se realizara entre pertenencias que correspondieren a un mismo concesionario minero, porque ello podría prestarse para tolerar una transferencia a tercero de la pertenencia superior, dejando vigente la inferior, con los consiguientes perjuicios que podrían significar para el concesionario de buena fe y para el desarrollo de la actividad minera.

$\left.5^{\circ}\right)$ Que así planteado el asunto, resulta conveniente precisar que la modificación introducida por la ley 19.573 el artículo 27 del Código de Minería, en cuanto agregó la frase final: "El juez velará por la observancia de esta prohibición" no ha tenido el carácter de una modificación sustantiva. En verdad, no innova en nada, y sólo ha venido en ratificar la misma disposición legal primitiva que informa que "sobre las sustancias concesibles existentes en terrenos cubiertos por una concesión minera no puede constituirse otra"

$6^{\circ}$ ) Que en concreto, el juez aquo ha tenido como cierta la existencia de una superposición con el sólo mérito del informe del Servicio Nacional de Geología y Minería agregado a fojas 46 . Sobre el particular, conviene hacer las siguientes consideraciones.

a) Como ya se ha visto, el artículo 83 del Código de Minería señala que en caso de que el informe de SERNAGEOMIN indique que se ha producido algunas de las situaciones a que se refiere el artículo 80 (superposición), el juez deberá disponer la correspondiente publicación y cumplido lo anterior, ordenar la notificación personal al titular de las pertenencias presuntamente afectadas (esta última exigencia, como ya se ha dejado consignado, fue introducida por la misma ley que modificó el artículo 27). Lo anterior lleva a los sentenciadores a concluir que con el único antecedentes que emana del informe, el juez no podría de inmediato negar a la constitución de la concesión solicitada.

b) Efectuada la notificación, dice el artículo 83 del Código de Minería, el afectado podrá, dentro del plazo de sesenta días, oponerse a la constitución de las pertenencias, debiendo con su presentación acompañar copia auténtica de la solicitud de mensura o del acta de mensura en su caso y del plano respectivo, si correspondiere. Si no cumple con las exigencias anteriores, la oposición será rechazada de plano.

Tales exigencias ratifica, entonces, lo concluido en cuanto el sólo anuncio de superposición que efectúa SERNAGEOMIN, no basta para denegar una sentencia constitutiva. Es claro, pues aún cuando se haya pre- 
sentado oponente, si no acompaña todos los antecedentes relativos a su mensura, los que necesariamente deberá ponderarlos el juez, tal oposición deberá ser rechazada de plano.

c) El mismo artículo 84 regla el procedimiento de oposición, concluyendo que si se rechaza la demanda (oposición) en todas sus partes, dictará la sentencia constitutiva de la pertenencia del demandado. Si la acoge en parte, determinará el terreno sobre el que podrá volver a mensurar aquél, y si acoge en su totalidad la demanda, declarará extinguidos los derechos del interesado y ordenará cancelar las correspondientes inscripciones.

$\left.7^{0}\right)$ Que de lo expuesto, se colige que el juez quedará en situación de dictar sentencia definitiva en el procedimiento de constitución de la pertenencia en los siguientes casos: a) Cuando el informe del Servicio Nacional de Geología y Minería es favorable sobre los aspectos técnicos y no señala que se ha producido alguna de las situaciones de sobreposición; b) Cuando habiéndose formulado objeciones de carácter técnico, éstas sean contradichas por el interesado aceptadas por el juez o debidamente subsanadas, como lo señala el artículo 82; c) Cuando habiendo el Servicio alertado acerca de una superposición, se hubiese deducido oposición y en definitiva tal oposición fuese rechazada por sentencia ejecutoriada d) Cuando la oposición deducida sea rechazada de plano por no haberse deducido cumpliendo con las formalidades que indica el artículo 84 en su inciso $2^{\circ}$ y e) Cuando habiendo informado el Servicio acerca de una superposición, publicada y notificada tal circunstancia, no se hubiere deducido oposición dentro de plazo legal.

$\left.8^{0}\right)$ Que siguiendo con la idea anterior, producida algunas de las situaciones señaladas, el juez deberá examinar los autos y si reúnen los requisitos legales, dictará la sentencia constitutiva de la pertenencia, así lo dice el artículo 85 del Código de Minería. Esta norma, a juicio de los sentenciadores debe ser entendida en el sentido de que el juez deberá examinar si se han cumplido con todas las formalidades legales de todo el proceso constitutivo, no pudiendo ser obstáculo para dictar sentencia favorable, la alarma de superposición que pudiere contener el informe del Servicio Nacional de Geología y Minería, si cumplidas todas las normativa de publicidad de tal hecho (y que el juez debe velar para ello) no se hubiese deducido oposición o esta hubiese sido rechazada de plano. No se podría entender, a la luz de toda la normativa procedimental de constitución de la concesión minera, de que el juez, asilado en los artículos 27 y 85 , tomase el papel del presunto perjudicado, a veces supliendo su desconocida voluntad (recordar que esta oposición es facultativa) y con el sólo mérito de alarma de superposición contenida en el informe de SERNAGEOMIN, se negase a dictar sentencia constitutiva.

$\left.9^{\circ}\right)$ Que en el caso de autos, sucede que la eventual superposición parcial, que acusa el informe del Servicio Nacional de Geología y Minería, se produciría respecto de las pertenencias mineras TAURO 1 al 77 que figuran inscritas a nombre de la propia constituyente Compañía Minera Carmen de Andacollo. Si ya se concluyó que en el evento que las pertenencias fuesen de un tercero "afectado" (como lo denomina el 
artículo 83) y éste no hiciera valer sus derechos en tiempo y forma, nada impediría al juez dictar sentencia constitutiva, forzoso resulta también concluir que en el caso de una autosuperposición (en donde no existiría "el afectado"), el juez tendría que llegar a la misma decisión, debiendo eso sí, que consignar en la sentencia constitutiva, conforme con las exigencias previstas en el artículo 87 del Código de Minería, la circunstancia acusada por SERNAGEOMIN.

$10^{\circ}$ ) Que a mayor abundamiento, no existe norma expresa que prohiba la autosuperposición y lo que es más, del estudio de la historia fidedigna de la Ley 19.573 relativa a la modificación efectuada al artículo 27 del Código de Minería, se desprende que el legislador quiso dejar expreso testimonio de que la prohibición de superposición no alcanza al caso de la autosuperposición (Diario de Sesiones del Senado, Legislatura 336 Extraordinaria, Sesión 31 de 21 de enero de 1998; y Sesión 10, de 22 de abril de 1998, Legislatura 337 Extraordinaria)

Por estos motivos y disposiciones legales citadas, SE REVOCA la resolución apelada de veintiséis de marzo del presente año, escrita a fojas 59 y siguientes, y en su lugar se resuelve de que el juez no inhabilitado que corresponda, procederá a dictar la sentencia constitutiva de la concesión solicitada "Pamela 1 al 60", la que deberá con todos los requisitos señalados en el artículo 87 del Código de Minería, teniendo presente lo señalado en el motivo noveno de esta sentencia.

Regístrese y devuélvase.

Redacción del ministro don Juan Pedro Shertzer Díaz.

Rol № 23.234.-

PRONUNCIADO POR LOS MINISTROS TITULARES DON JUAN PEDRO SHERTZER DIAZ, DON IORGE ZEPEDA ARANCIBIA Y ABOGADO INTEGRANTE DON JOSE ILABACA SAEZ

\section{RUBEN MORALES NEYRA}

\section{SECRETARIO TITULAR}

La Serena, tres de noviembre del mil novecientos noventa y nueve, notifiqué por el Estado Diario la resolución precedente. 